\title{
Modeling suspended sediment concentration using multilayer feedforward artificial neural network at the outlet of the watershed
}

\section{DANIEL PRAKASH KUSHWAHA AND DEVENDRA KUMAR}

Received : 23.03.2017; Revised : 17.07.2017; Accepted : 01.08.2017

See end of the Paper for authors' affiliation

Correspondence to :

\section{DANIEL PRAKASH}

\section{KUSHWAHA}

Department of Soil and Water

Conservation Engineering, College of Technology, G.B.

Pant University of Agriculture and Technology, Pantnagar, U.S. NAGAR (UTTARAKHAND) INDIA

Email : danielprakash45499@ gmail. com
-ABSTRACT : Eight multilayer feedforward artificial neural network based models were developed to predict daily suspended sediment concentration for the Baitarani river at Anandpur gauging station using daily discharge and daily suspended sediment concentration. The 30 years data (June 1977 to September 2006) used in this study was divided into two sets viz. a training set (19771996) and a testing set (1997-2006). Artificial neural networks (ANN) models were calibrated by using multilayer feedforward back propagation neural networks with sigmoid activation function and Levenberg-Marquardt (L-M) learning algorithm. The performance of the developed models was evaluated qualitatively and quantitatively. In qualitative evaluation of models, the observed and the computed suspended sediment concentration were compared using sediment hydrographs and scatter plots during testing period. Akaike's information criterion (AIC), correlation co-efficient (r), mean square error (MSE), root mean square error (RMSE), minimum description length (MDL), co-efficient of efficiency (CE) and normalized mean square error (NMSE) indices were used for quantitative performance evaluation of the models. Results on the basis of qualitative and quantitative evaluation indicate that M-6 model with (7-5-5-1) network architecture is better than all models at Anandpur station and it was also found that artificial neural network based model is better than physics based models such as sediment rating curve and multiple linear regression.

- KEY WORDS :Multilayer feedforward artificial neural networks, Levenberg-Marquardt (L-M) learning algorithm, Sigmoid activation function, Suspended sediment concentration modeling, Sediment rating curve, Multiple linear regression.

- HOW TO CITE THIS PAPER : Kushwaha, Daniel Prakash and Kumar, Devendra (2017). Modeling suspended sediment concentration using multilayer feedforward artificial neural network at the outlet of the watershed. Internat. J. Agric. Engg., 10(2) : 302-313, DOI: 10.15740/HAS/IJAE/10.2/ 302-313. 